\title{
Effects of Virtual Laboratory Instructional Strategy on Students 'achievement In Chemistry Practical among Senior Secondary Schools in Minna Metropolis, Niger State
}

\author{
Chado, $\mathrm{A}^{1}$, Dalhatu, $\mathrm{B}^{2,}$ Mohammed, $\mathrm{S}^{3}$ \\ ${ }^{1}$ Ph.D., Science Education Department, School of Science and Technology Education \\ Federal University of Technology Minna \\ ${ }^{2}$ Ph.D., Science Education Department, School of Science and Technology Education \\ Federal University of Technology Minna \\ ${ }^{3}$ Science Education Department, School of Science and Technology Education \\ Federal University of Technology Minna \\ muhammadsgini@gmail.com (Corresponding Author)
}

\begin{abstract}
This study adopted quasi experimental design. Pretest, posttest experimental and control groups design was adopted. Two research questions and two hypotheses formulated and tested at 0.05 level significance. The population for the study comprises of 3395 senior secondary school chemistry students in Minna metropolis, Niger state. A multi-stage sampling technique was employed, which were clustered into A \&B with a sample size of 120 . Four schools were randomly sampled. Balancing of Chemical Equation Achievement Test (BOCEAT). BOCEAT was validated by three experts, one in Measurement and Evaluation and two science educators in the Department of Science Education of the Federal University of Technology, Minna for both face and content validation. Test, retest was administered to ascertain reliability index for BOCEAT and the data collected from both the experimental and control groups for the reliability were statistically analyzed using t-test to calculate the internal consistency which yielded 0.87 . The data collected for the study were analyzed using mean and standard deviation to answer research questions and t-test to test the formulated hypothesis at 0.05 levels of significance. Findings from the study showed that virtual laboratory instructional package impacted positively on students' academic achievement in chemistry practical than traditional method. On the mean achievement scores of male and female students taught balancing of chemical equations using virtual laboratory strategy, female did better than the male. Based on the findings of the study, chemistry teachers should be encouraged to use virtual laboratory strategy while teaching chemistry concepts especially balancing of chemical equation.
\end{abstract}

Keywords: Achievement, gender. Virtual laboratory

\section{Introduction}

Chemistry is one of the science subjects offered in most of secondary schools in Nigeria and also a major requirement for admission into science based fields of studies such as Medicine, Engineering, Pharmacy and Agriculture in all institutions of learning, [1] , [2].
The study of chemistry has been and will remain of tremendous importance to mankind as it is capable of explaining natural phenomena and everyday occurrences. In Nigeria, Chemistry is one of the important science subjects taught at all Senior Secondary School (SSS) level. It is one of the core science subjects that students are required to pass at credit level in order to qualify for admission into tertiary institutions to pursue science-based programmes. In spite of this central and important position of chemistry among others science and related disciplines, studies have revealed that, academic achievement of 
students in chemistry at Senior Secondary School Certificate Examination (SSSCE) has consistently been very poor and unimpressive The outbreak of covid-19 pandemic has no doubt affected every sphere of human endeavours from social, economic, educational and sporting activities around the globe. The consequences of this impact is mostly felt in education as many students were out of class for several months except those schools with high tech facilities who were able to engage their learners through an e-learning or virtual classes. [3.

Virtual laboratories provide simulated versions of traditional laboratories referring to a learner-centred approach in which the learner is provided with objects that are virtual representations of real objects used in traditional laboratories Virtual laboratories may contribute to teaching and learning processes by giving students the opportunity to learn by doing, providing them with intriguing and enjoyable activities urging them to discover, and guaranteeing an active classroom interaction by means of discussions and debates [4].

An alternative learning environment, called a virtual laboratory, can help to make this crucial educational application available to students. Virtual laboratories provide students with meaningful virtual experiences and present important concepts, principles, and processes. By means of virtual laboratories, students have the opportunity of repeating any incorrect experiment or to deepen the intended experiences. Moreover, the interactive nature of such teaching methods offers a clear and enjoyable learning environment [5]. They are also beneficial to study advanced concepts such as relativity and experimentation that would not be studied or realized in traditional laboratory settings They can be more easily assembled and more properly used than real laboratory equipment, and therefore are more time efficient than traditional hands-on laboratories [6].

Literatures on the use of virtual laboratories demonstration in science courses are scarce in Nigeria however; few research literatures reported that students exposed to virtual laboratory perform better than the traditional laboratory demonstration [7],

Achievement is an important academic factor that is influenced by teaching strategies. Achievement is the process of getting something done effectively and successfully using effort and skills aimed at accomplishment of academic goals viewed achievement as measurable changes in students' behaviour in academic as a result of exposure to a given concept.

Gender issues have been linked with achievement of students in academic tasks in several studies but without any definite conclusion. Some studies revealed that male students performed better than the female in science courses. For instance, found that male students performed better than female in interactive physics, while, found that girls performed better than boys using science process skills method of teaching. [8],

However gender had no effect on academic achievement of students. Base on the foregoing, the researcher determined the effect of Virtual laboratory instructional package on
Achievement in balancing of chemical equation among selected Senior Secondary School Students in Minna metropolis [9].

\section{Methodology}

\section{Statement of problem}

It is noticeable among the secondary students having challenges comprehending the concept of Balancing of chemical equations which occupy a central position in understanding some concepts such as; stoichiometry, chemical arithmetic, Faraday's laws of electrolysis, volumetric analysis. Balancing of chemical equation is very fundamental and very important chemical skill in chemistry.

Chief Examiners report on the West African Senior School Certificate on students' weaknesses in balancing of chemical equations. For example, the WAEC Chief Examiners report on the May/June 2012, 2015 and 2018 reported that candidate's weakness included poor knowledge of symbols, formulae and equation and inability to balance equations correctly. It is in view of this that the study determined the effect of virtual laboratory instructional strategy on achievement in balancing of chemical equation among senior secondary school students in Minna, Metropolis.

\section{Research Questions}

The following research questions were raised to guide this study.

i.Is there any difference between the mean achievement scores of students taught balancing of chemical equations using virtual laboratory strategy and those taught using traditional method?

ii. What is gender effect on achievement of students taught using virtual laboratory instructional strategy?

\section{Hypotheses:}

The following null hypothesis ware tested at 0.05 level of significance:

- HO1 There is no significant difference between the achievement score of students taught balancing of chemical equations using virtual laboratory instructional strategy and those taught with traditional method.

- HO2 There is no significant difference between gender achievement score of students taught balancing of chemical equations using virtual laboratory instructional strategy.

\section{Objective of the Study}

This study adopted quasi experimental design. It is type of experimental research method used to estimate the causal impact of an intervention on target population without random assignment, using a pretest, posttest, control design. This research design sought to establish the cause-effect relationship between the independent and dependent variables .Multi-stage sampling techniques were employed for the study. Firstly, a cluster sampling technique was used to sample the schools in to A and B groups. Secondly, a purposive sampling technique employed to select two schools from cluster A, and two from cluster B. Thirdly, A Proportionate stratified simple random sampling technique was employed to categories the sample based on gender of the students (male and female). Fourthly, S.S. II chemistry class sample size was randomly selected using simple random technique. One out of the four selected secondary school was used for pilot study and the other three 
secondary schools were used for the main study in minna metropolis.

From the total sample size, the students were randomly selected into the experimental group (virtual laboratory instructional strategy) and control group (traditional laboratory strategy) respectively for the study. Population of the study comprised of 3395 chemistry students (2002/2021) in the senior secondary schools within Minna metropolis. The target population of the study was 2090 SSII Chemistry students, made up of 986 male and 1104 female students. 120 sample population was drawn.

The research instrument, Balancing of Chemical Equation Achievement Test (BOCEAT) comprised of section A and B. 20 questions based on balancing of chemical equation. section A contained ten multiple choice objective questions with four response options A - D, while section B contained ten question which requires two responses of skeletal and balancing of equation, was administered to the entire research subjects by the researcher and two trained research assistants. Enough copies of the research instruments based on the number of the respondents were provided for all the research assistants. The research assistants taught both the experimental and control groups using virtual laboratory strategy and traditional laboratory method respectively. The pre BOCEAT was administered to the two groups before the treatment. Two (2) weeks after the treatment, the Post BOCEAT was administered to all the subjects after then. The same BOCEAT was administered on the experimental group and the control group as a retention test, giving two weeks interval. The reliability of the research instrument was determined using t-test and the correlation coefficient of 0.82 was established for students' achievement in chemistry practical among senior secondary schools in Minna metropolis. Data collected from the study were analysed using t-test statistics. The significant difference was ascertained at 0.05 alpha level.The Statistical Package for social Science (SPSS) version 23.0 was used for the analysis..

\section{Results}

\section{Research Question one}

Is there any difference between the mean achievement scores of students taught balancing of chemical equations using virtual laboratory strategy and those taught using traditional method? This research question was answered using mean, and standard deviation. Summary of the result is presented in table1.
Table (1) show mean and standard deviation of students' achievement score of students taught balancing of chemical equations using virtual laboratory instructional strategy and those taught using traditional method. The findings show the computed mean score of 4.93 with standard deviation of 2.577 for the students taught using traditional method and mean score of 7.20 with standard deviation of 3.643 for the students taught using virtual laboratory instructional strategy. This gives mean difference of 1.066 between the achievements.

\section{Research Question Two}

What is gender effect on achievement of students taught using virtual laboratory instructional strategy?

Table (2) Mean, Standard deviation and Mean difference of gender effect of students taught using virtual laboratory instructional strategy

\begin{tabular}{|c|c|c|c|c|c|}
\hline & Gender & $\mathrm{N}$ & Mean & $\begin{array}{c}\text { Std. } \\
\text { Deviation }\end{array}$ & $\begin{array}{c}\text { Std. Error } \\
\text { Mean }\end{array}$ \\
\hline $\mathrm{SCO}$ & Male & 30 & 6.93 & 3.140 & .573 \\
\hline $\mathrm{RE}$ & Female & 30 & 13.88 & 2.559 & .522 \\
\hline
\end{tabular}

Table (2)show mean, standard deviation and mean difference of gender effect of students taught using virtual laboratory instructional strategy and those taught using traditional method. The findings show the computed mean scoreof 6.93 with standard deviation of 3.140 for the students taught using traditional method and mean score of 13.88 with standard deviation of 2.559 for the students taught using virtual laboratory instructional strategy. This gives mean difference of 6.95 between the genders.

\section{Hypothesis One}

There is no significant difference between the achievement score of students taught balancing of chemical equations using virtual laboratory strategy and those taught with conventional method.

Table (3) Mean, Standard deviation and Mean difference of gender effect of students taught using virtual laboratory instructional strategy

Table (1) Mean, Standard deviation and Mean difference students' achievement score of students taught using virt laboratory instructional strategy and those taught usi traditional method

\begin{tabular}{|c|c|c|c|c|c|c|c|c|c|c|}
\hline & & \multirow[b]{2}{*}{$\mathrm{F}$} & \multirow[b]{2}{*}{ Sig. } & \multirow[b]{2}{*}{$\mathrm{t}$} & \multirow[b]{2}{*}{ Df } & \multirow{2}{*}{$\begin{array}{l}\text { Sig. } \\
\text { tailed }\end{array}$} & \multirow{2}{*}{$\begin{array}{l}\text { Mean } \\
\text { Differe } \\
\text { nce }\end{array}$} & \multirow{2}{*}{$\begin{array}{l}\text { Std. } \\
\text { Error } \\
\text { Diffe } \\
\text { rence }\end{array}$} & \multicolumn{2}{|c|}{$\begin{array}{l}\text { 95\% Confidence } \\
\text { Interval of the } \\
\text { Difference }\end{array}$} \\
\hline & & & & & & & & & Lower & Upper \\
\hline Group & $\begin{array}{l}\text { Equal } \\
\text { Variances } \\
\text { Assumed }\end{array}$ & 5.0 & .027 & -2.19 & 117 & .030 & -1.2 & .578 & -2.41 & -.126 \\
\hline . & $\begin{array}{l}\text { Equal } \\
\text { Variances } \\
\text { Not } \\
\text { Assumed }\end{array}$ & & & -2.19 & $\begin{array}{c}104 \\
.2\end{array}$ & .031 & -1.2 & .579 & -2.41 & -.121 \\
\hline
\end{tabular}


The table above shows the t-test result of student achievement test. The result reveals that there is statistically significant difference between the test score since the sig (2-tailed) is less than 0.05 (i.e $0.030<0.05$ ) from the group statistics table, we will see that the group that was thought using virtual laboratory strategy had higher score than those that were thought using traditional method i.e. (7.20>5.93). On this basis, the null hypothesis wa rejected; therefore there is significant difference in the achievement of students taught balancing of chemical equations using the virtual laboratory strategy and those taught balancing of chemical equations with the traditional method.

\section{Hypothesis Two}

There is no significant difference between gender achievement score of students taught using virtual laboratory instructional strategy

Table (4) Mean, Standard deviation and Mean difference of gender effect of students taught using virtual laboratory instructional strategy

\begin{tabular}{|c|c|c|c|c|c|c|c|c|c|c|}
\hline & \multirow[b]{2}{*}{$\mathrm{F}$} & \multirow[b]{2}{*}{ Sig. } & \multirow[b]{2}{*}{$\mathrm{T}$} & \multirow[b]{2}{*}{ df } & \multirow{2}{*}{$\begin{array}{c}\text { Sig. } \\
\text { tailed }\end{array}$} & \multirow{2}{*}{$\begin{array}{c}\text { Mean } \\
\text { Difference }\end{array}$} & \multirow{2}{*}{$\begin{array}{c}\text { Std } \\
\text {. Error } \\
\text { Differe } \\
\text { nce }\end{array}$} & \multicolumn{2}{|c|}{$\begin{array}{c}95 \% \\
\text { Confidence } \\
\text { Interval } \\
\text { Of The } \\
\text { Difference }\end{array}$} \\
\hline & & & & & & & & & Lower & Upper \\
\hline \multirow[t]{2}{*}{ Score } & \begin{tabular}{|l|} 
Equal \\
variances \\
assumed
\end{tabular} & 1.81 & .184 & -8.74 & 52 & .000 & -6.94 & .793 & -8.53 & -5.35 \\
\hline & \begin{tabular}{|l|} 
Equal \\
variances \\
not \\
\end{tabular} & & & -8.95 & 51.97 & .000 & -6.94 & .776 & -8.49 & -5.38 \\
\hline
\end{tabular}

Significant at $\mathrm{P}<0.05$

Table (4) above shows the t-test result of student achievement test. The result reveals that there is statistically significant difference between the test scores of the male and female group, since the sig (2-tailed) is less than 0.05 (i.e $0.000<0.05$ ) .From the group statistics table, we will see from the mean difference of the group that female group is higher than the male group i.e. $(13.88>6.93)$. On this basis, the null hypothesis is rejected; therefore there is significant difference in the achievement of male and female students taught balancing of chemical equations using the virtual laboratory instructional strategy and those taught balancing of chemical equations using traditional method.

\section{Discussion}

The findings of the study revealed that it is profitable that virtual laboratory instructional strategy has effects on students'achievement compared to students taught balancing of chemical equations using the traditional method. This concurs with Brinson, (2015) who opined that virtual laboratory provides students with opportunities such as enriching their learning experiences; conducting experiments as if they were in real laboratories; and improving their experiment related skills such as manipulating materials and equipment, collecting data, balancing of chemical equations, completing experiment process in an interactive way (with boundless supplies), and preparing experiment reports. Furthermore, some researchers even argue that performing experiments within a virtual environment is more effective than performing experiments in real laboratories (McCoyKozma, Chin, Russell, \& Marx in Tatli\&Ayas, 2013; Browne, 2014).
The study also revealed that there is significant difference in the achievement of male and female students taught balancing of chemical equations using virtual laboratory instructional strategy. This finding that the achievement of male and female students shows statistical difference contradicts the results of Harding and Parker in Giginna (2013), who observed that science education, is strongly influenced by gender in most but not all the cultures. This is also supported by Okeke (2014) who observed that females are grossly underrepresented in science, technology and mathematics. The authors also stated that males are not superior to females intellectually, and any difference is due to upbringing and cultural beliefs.

The female subjects performing better than male is in consonance with Shaibu and Mari in Giginna (2013)who observed that female students are significantly better than their male counterparts and that there was significant difference between the male and female students in their ability to solve quantitative problems. Nworguin Giginna (2013) and Egbugharain Giginna (2013) found that female students perform better than their male counterparts in science. Similarly, Ahiakwoin Giginna (2013)carried out research on cognitive style and students ${ }^{\text {ee }}$ problem solving behavior in chemistry. It was found that there was sex difference in performance using chemistry process skill test. In this study, girls performed better than boys.

\section{Conclusion}

From the findings of this study, it revealed that the group that was thought using virtual laboratory strategy had higher score than those that were thought using traditional method i.e. (7.20>5.93).On this basis, there is significant difference in the achievement of students taught balancing of chemical equations using the virtual laboratory strategy and those taught balancing of chemical equations with the traditional method.

It also revealed from the group statistics table that the mean difference of the female group is higher than the male group i.e. $(13.88>6.93)$.This showed that there is significant difference in the achievement of male and female students taught balancing of chemical equations using virtual laboratory instructional strategy.

\section{Recommendations}

Based on the major findings of this study, the following recommendations are proffered.

i.Chemistry teachers should be encouraged to use virtual laboratory strategy while teaching chemistry concepts especially chemical balancing of equation.

ii.Educational agencies and other stakeholders should organize workshops and seminars on the use of virtual laboratory strategy to enhance better performance of secondary school students particularly in Chemistry

iii.(iii).NERDC, individuals and any establishment involved in production of chemistry resource materials, teaching aids like charts, models, and textbooks should develop and produce virtual laboratory materials in chemistry and other sciences to help the teachers.

iv.The instructional designers, computer programmers, material developers should develop relevant virtual laboratory strategy packages for use within the Nigerian school systems. 


\section{References}

[1] Azare, G.D. (2017). Progress, problems and progress Reports on state of science Education in Nigeria. International Journal of Science, Technology, Mathematics and Education. 6(3),34-42

[2] Asiyai, R. I. (2016)-Enhancing Chemistry Teaching in Secondary Schools through Concept Mapping Instructional Strategy. In Nzewi, U.(Ed.)Proceedings of the 46thAnnual Conference of Science Teachers Association of Nigeria.205-209.Ibadan Nigeria: Heinemann Educational Books.

[3] Kuhfeld, M., Soland, J., Tarasawa, B., Johnson, A., Ruzek, E., \& Liu, J. (2020). Projecting the potential impactof COVID-19 school closures on academic achievement. Educational Researcher 49(8), 549-565

[4] Lkhagva, O., Ulambayar, T., \&Enkhtsetseg, P. (2015) Virtual laboratory for physics teaching. In Proceedings of the International Conference on Management and Education Innovation, IPEDR, 37 (062) Singapore (PP.319-323). Retrieved from: http://www.ipedr.com/vol37/062-ICMEI2012-E10015.pdf

[5] Jeschke, S., Richter, T., \& Zorn, E. (2016). Virtual laboratory in mathematics and natural sciences. International Conference onTechnology Supported Learning \& Training: Online Educa Berlin. Retrieved February 10, 2010, from: http://www.ibi.tuberlin.de/diskurs/veranst/online_educa/ oeb_04/Zorn\%20TU.pdf

[6] Aldrich, C. (2016). Learning by doing: A comprehensive guide to simulations, computer games, and pedagogy in -eLearning and other educational experience. San Francisco, CA: Wiley, Pfeiffer

[7] Gambari, A. I., Olumorin, C. O.; \& Yusuf, M. O. (2013) Effectiveness of computer-supported jigsaw in cooperative learning strategy on the performance of senior secondary school students in physics.Global Media Journal (Pakistan Edition), 6(2),1-12. A Publication of AllamaIqbal Open University,Pakistan.

[8] Lawrence, O. F. (2017). Investigating the effectiveness of virtual laboratories in an undergraduate biologycourse. The Journal of Human Resource and Adult Learning, 7(2), 110-116.

[9] Dobson, J. (2016). evaluation of the virtual physiology of exercise laboratory program. Advances in PhysiologyEducation, 33, 335342 .

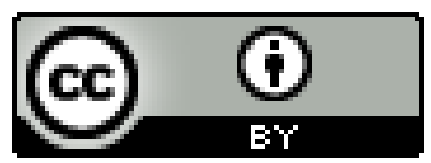

